\title{
The Importance of CT Pneumocolon in Detecting Colonic Lesions
}

\author{
Saadoon Zghair Haidar Al -Yassen (MBCHB,MDR) ${ }^{1}$, Mansour Edan Dawood \\ $(\mathrm{MBCHB}, \mathrm{MDR})^{2}$ and Mustafa Abdulkareem Salman $(\mathrm{MSc})^{3}$ \\ ${ }^{1}$ Radiologist in Khaneqeen Hospital, Diyala, Iraq \\ ${ }^{2}$ Al-Zehraa Hospital, Diyala, Iraq \\ ${ }^{3}$ College of Medicine ,University of Diyala, Diyala, Iraq \\ Correspondence Address: \\ Mansour Edan Dawood \\ Department of Medicine, Baquba Teaching Hospital, Diyala, Iraq \\ email: Mansouraljuhashi1971@gmail.com
}

Received: 15 July 2021

Accepted: 22 September 2021

Published: 25 December 2021

Diyala Journal of Medicine 2021:21(2): 76-82

\begin{abstract}
Background: Colonic masses are clinically important because some of them are malignant and others have a tendency to become malignant such as polyps. CT pneumocolon may have a role in the evaluation and diagnosis of these masses.

Objective: To determine the accuracy of computed tomography (CT) pmeumocolon in the detection of colonic masses compared with colonoscopy.

Patients and Methods: A total of 60 patients with colorectal symptoms underwent evaluation for the presence of colorectal neoplasms by using both colonoscopy and CT pneumocolon and a comparison was made between them.

Results: On colonoscopy, 10 out of 60 patients were having a negative colonoscopy. The results of colonoscopy of the other 50 patients were as follow; three out of fifty colonoscopies revealed invasive colorectal carcinomas in threse patients. The remaining 47 colonoscopies for 47 patients revealed benign polyps. The sizes of these polyps were as follows; ( 6 polyps were $>1 \mathrm{~cm}$ in diameter), (17 polyps were $6-9 \mathrm{~mm}$ ), and ( 24 polyps were $\leq 5 \mathrm{~mm})$. CT pneumocolon detected all 3 malignant masses seen and biopsied by colonoscopy, but only (28 single polyps) which according to their size (4 polyps were $\geq$ $1 \mathrm{~cm})$, (11 polyps were $6-9 \mathrm{~mm})$ and $(13$ polyps $\leq 5 \mathrm{~mm})$, this gives CT pneumocolon a sensitivity of (63\%), specificity of (70\%) and accuracy (63\%).

Conclusion: CT pneumocolon has high sensitivity and specificity for a detection of largesized masses, but not for small ones. CT pneumocolon may be suitable for investigating patients with symptomatic colorectal masses noninvasively.
\end{abstract}

Keywords: Pneumocolon, colonoscopy, polyp, colonic carcinoma 
DOI: https://doi:10.26505/DJM.21026100715 , (CAuthors, 2021, College of Medicine, University of Diyala.

This is an open access article under the CC BY 4.0 license (http://creativecommons.org/licenses/by/4.0/)

\section{Introduction}

Colonic masses can be benign or malignant. These masses either originate in the colon or metastatic from other organs to the colon [1]. Many colonic malignant tumors are treatable if the diagnosis is done early. Carcinoma of the colon usually begins in the mucosal layer, then grows and invades deeper through the colonic wall. Cancer cells can spread through the blood and lymphatic vessels once the disease reaches the submucosa [1]. Deeper invasion can even perforate the colonic serosal layer resulting in fecal peritonitis at which time diagnosis will be delayed [2].

CT pneumocolon is an alternative less invasive method to colonoscopy using CT scan images to visualize the colon for any polyps or masses in symptomatic patients. CT pneumocolon have a good advantage when compared with colonoscopy in the detection of colonic masses because it is less invasive. It is also associated with fewer complications and can give good information that supports the findings of colonoscopy [4]. CT pneumocolon through using the x-ray and computer can provide two and three dimensions section of the colon [4]. Examination starts from the distal part of the rectum to the lower end of a small bowel, displaying the images on a screen [4]. Furthermore, CT pneumocolon can show masses without the need for camera insertion into the colon. Colonic lesions that can be visualized by CT pneumocolon include large tumors some large polyps, and diverticular [4].

CT images were obtained in the prone and supine positions during prolonged breathholding. Then these images are reconstructed in axial, sagittal and coronal planes [5]. CT pneumocolon as colonoscopy also needs colonic preparation with oral laxative, but without sedation or analgesia (unlike colonoscopy). CT pneumocolon is so safe and rarely has a significant complication [6]. Unlike colonoscopy, CT pneumocolon can see extra-colonic intra-abdominal organs, giving good information about extra-colon deposit [6]. The current study aimed to evaluate the importance and the accuracy of computed tomography (CT) pneumocolon in detecting colonic masses examined with the usual colonoscopy.

\section{Patients and Methods}

This is a cross-sectional study of sixty patients who underwent $\mathrm{CT}$ pneumocolon then colonoscopy to assess the accuracy and sensitivity of the former in detecting colonic lesions. The study was achieved at the department of radiology in Al- Imamein AlKademein hospital during the period September 2014 - September 2015. A total of sixty symptomatic patients were enrolled in the study. The average age of the patients is 61.5 years. Thirty-three $(55 \%)$ were males and twenty-seven (45\%) were females. All of the sixty patients were having symptoms suggesting colonic disease. Those patients were referred from gastrointestinal tract 
(GIT) unit for assessing the colon for any lesions by performing CT pneumocolon and colonoscopy. Excluding criteria include patients who have a history of inflammatory bowel disease, pregnant females, patients who have no satisfactory examination. The data collected included, patient's name, age, sex, case history, surgical history and date of examination. All patients had their bowel adequately prepared before the examination. CT pneumocolon examination was achieved by placing the patient in the left lateral position and a rectal tube inserted. Intravenous hyoscine N-butyl-bromide (20 mg) was administered. Subsequently, the colon is gently insufflated with air till the patient feels mild abdominal discomfort. Also, colonic distension was assessed. Scanning was started sixty seconds later, passing caudocranially from symphysis pubis bone to the diaphragm. The procedure didn't require sedation. The $\mathrm{CT}$ pneumocolon was performed during breath-hold once the scan level passed higher than the true pelvis. Supine and prone pelvis views were obtained in the majority of patients. Interpretation of the scan pictures was performed using an extended digital computer (CT somatom definition AS forty-six slice Siemens medical system Germany). In addition, the images were viewed by a pair of independent radiologists to minimize inter-observer errors. After a minimum of one hour following completion of the CT scan, a colonoscopy was performed, Patients were sedated with intravenous pethidine. Colonoscopies were performed using the customary video colonoscopy. The endoscopist was unaware of the CT pneumocolon results. The examination level of the colon was at a maximum at $170 \mathrm{~cm}$ from the anal verge. Flexible sigmoidoscopy was used, and abnormalities were recorded where ever seen. Polyp size was estimated directly when retrieved using biopsy forceps. The colon was divided into four segments: right, transverse, left, and rectosigmoid and the polyps found were recorded to be found in which part of the colon. An agreement was evaluated between the two techniques depending on the size and site of the mass.

\section{Statistical analysis}

The data analyzed using frequencies and percentages only.

\section{Results}

Sixty patients were included in the current study. Ten patients were having a negative colonoscopy (no colonic lesions). Fifty lesions were revealed by colonoscopy and underwent histopathological examination. Forty-seven out of fifty patients (94\%) had benign pathology in the form of a single polyp and only 3 patients (6\%) had malignancy lesions. The distribution of lesions was as following: 24 polyps (48\%) were $<5 \mathrm{~mm}, 17$ (34\%) polyps were between 6- $9 \mathrm{~mm}, 6$ polyps $(12 \%)>10 \mathrm{~mm}$, and three $(6 \%)$ invasive carcinoma Table (1). When comparing colonoscopy with CT pneumocolon for sixty patients, it had been seen that fifty patients were having positive findings on colonoscopy, seven patients were truly negative (normal) in both colonoscopy and pneumocolon and three patients were having false positive findings on $\mathrm{CT}$ pneumocolon. 
Table (1): Distribution of lesions depending on real finding on colonoscopy

\begin{tabular}{|l|c|}
\hline \multicolumn{1}{|c||}{ Finding } & Colonoscopy \\
\cline { 2 - 3 } & (n.\%) \\
\hline \hline Polyp $\leq 5 \mathrm{~mm}$ & $24(48 \%)$ \\
\hline \hline Polyp 6-9 mm & $17(34 \%)$ \\
\hline \hline Polyp $\geq 10 \mathrm{~mm}$ & $6(12 \%)$ \\
\hline \hline Carcinoma & $3(6 \%)$ \\
\hline \hline Total & 50 \\
\hline
\end{tabular}

CT pneumocolon sensitivity was only $62 \%$ as it detected only 31 out of the 50 lesions seen by colonoscopy. These thirty-one lesions were distributed as follow; three lesions $(6 \%)$ which were proved malignant on colonoscopy and 28 (56\%) polypus lesions. Out of the 28 polypus lesions; 13 polyps $(46 \%)$ sized $\leq 5 \mathrm{~mm}, 11$ polyps $(39 \% \%)$ sized $6-9 \mathrm{~mm}$, and 4 polyps (14\%) sized >
$10 \mathrm{~mm}$. CT pneumocolon also recorded false negative results and as follow: 11 patients $(22 \%)$ sized $\leq 5 \mathrm{~mm}, \quad 6$ patients $(12 \%)$ sized $6-9 \mathrm{~mm}$ and 2 patients (4\%) sized $10 \mathrm{~mm}$ or more. Furthermore, CT pneumocolon recorded $7 / 50$ patients as having true negative results and 4/50 patients as having false positive lesions Table(2).

Table (2): Distribution of the lesions after performing CT pneumocolon in comparison with the real findings detected by colonoscopy

\begin{tabular}{|c|c|c|c|c|c|c|}
\hline \multirow{2}{*}{ Finding } & \multirow{2}{*}{$\begin{array}{c}\text { Colonoscopy } \\
\text { No. }\end{array}$} & \multicolumn{4}{|c|}{ CT } & \multirow{2}{*}{ Percentage } \\
\hline & & $\begin{array}{c}\text { True } \\
\text { positive }\end{array}$ & $\begin{array}{c}\text { False } \\
\text { negative }\end{array}$ & $\begin{array}{c}\text { True } \\
\text { negative }\end{array}$ & $\begin{array}{c}\text { False } \\
\text { positive }\end{array}$ & \\
\hline Polyp $\leq 5 \mathrm{~mm}$ & 24 & 13 & 11 & $\overline{0}$ & 2 & \multirow{4}{*}{$\begin{array}{c}\text { Accuracy } \\
63 \% \\
\text { Sensitivity } \\
62 \% \\
\text { Specificity } \\
70 \% \\
\end{array}$} \\
\hline Polyp 6-9 mm & 17 & 11 & 6 & 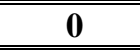 & 1 & \\
\hline Polyp $\geq 10 \mathrm{~mm}$ & 6 & 4 & 2 & $\mathbf{0}$ & $\mathbf{0}$ & \\
\hline Carcinoma & 3 & 3 & $\mathbf{0}$ & $\mathbf{0}$ & $\mathbf{0}$ & \\
\hline Total & 50 & 31 & 19 & 7 & 3 & 60 \\
\hline
\end{tabular}

The thirty-one lesions detected by $31 \mathrm{CT}$ pneumocolon were distributed as follow; 3 polyps $(10 \%)$ in the ascending colon, 6 polyps (19\%) in the transverse colon, 9 polyps $(29 \%)$ in the descending colon and 10 polyps (32.3\%) in the rectosigmoid. The three malignant lesions $(9.7 \%)$ were sited at the rectosigmoid CA Table (3) 
Table (3): Distribution of the lesions detected by CT pneumocolon in the colon in comparison with their real sites detected by colonoscopy

\begin{tabular}{|c|c|c|}
\hline & Colonoscopy & CT \\
\hline & No. & $\begin{array}{c}\text { True } \\
\text { Positive }\end{array}$ \\
\hline Ascending colon (polyp) & 8 & $3(10 \%)$ \\
\hline Transverse colon (polyp) & 12 & $6(19 \%)$ \\
\hline Descending colon (polyp) & 14 & $9(29 \%)$ \\
\hline Recto-sigmoid(polyp) & 13 & $10(32.3 \%)$ \\
\hline Recto-sigmoid (CA) & 3 & $3(9.7 \%)$ \\
\hline
\end{tabular}

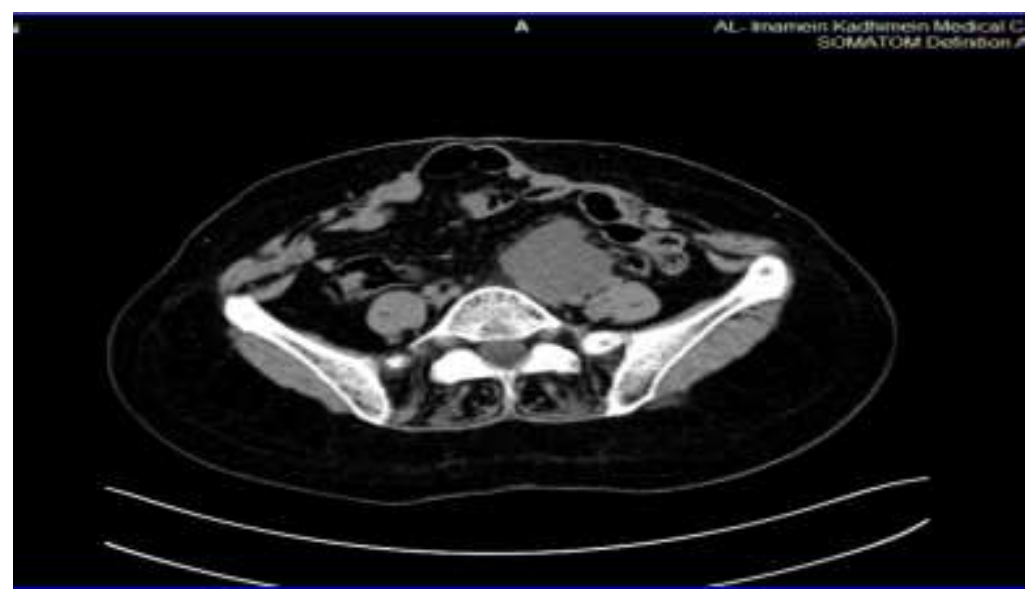

Figure (1): Female patient, 52 years old, presented with abdominal pain and rectal bleeding, CT pneumocolon showed a colonic mass (adenocarcinoma)

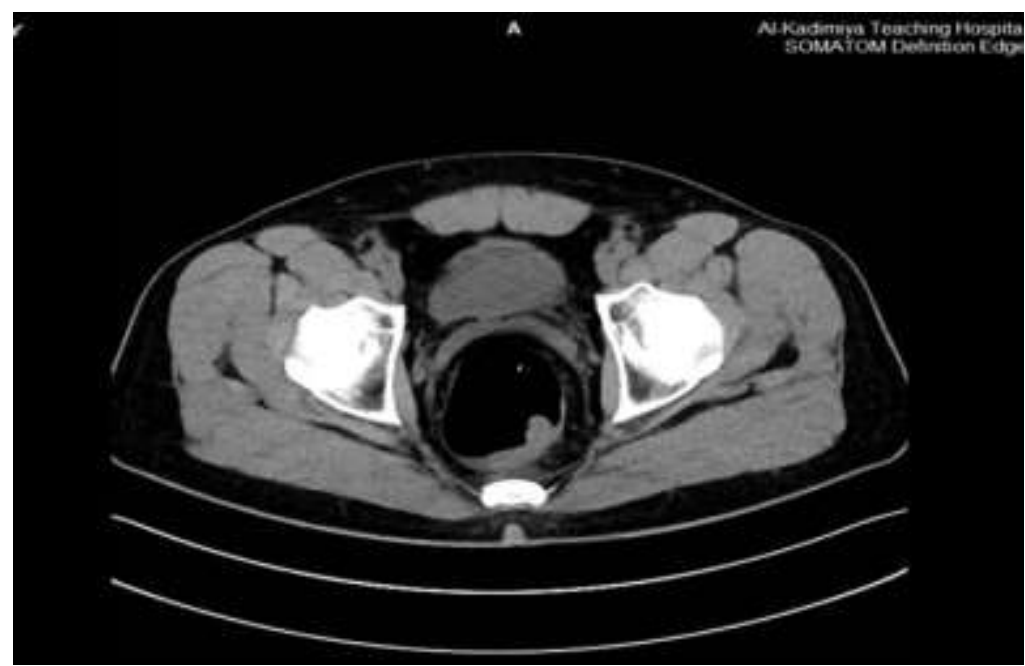

Figure (2): Male patient, 51 years, presented with abdominal pain and change in bowel habits, CT pneumocolon showed a sigmoid polyp

\section{Discussion}

A colorectal polyp may also be described as a mucosal elevation which is crucial due to the fact of their malignant potential, which depends upon the histology. There are multiple different types of polyps according 
to their histology (adenomatous, hyperplastic, inflammatory polyps). They occur sporadically or as a part of a polyposis syndrome. Most colorectal cancers are believed to originate from preexisting adenomatous polyps and the risk a malignancy is strongly related to the polyp's size. Colorectal polyps of $>1 \mathrm{~cm}$ diameter are clinically more important than smaller ones. An interval period of $10-15$ years is required for the polyps to evolve to invasive malignancy. This reflects the very slowgrowing.

The current study results revealed that CT pneumocolon had a poor overall sensitivity for diagnosing colonic polyps especially small polyps sizing less than $1 \mathrm{~cm}$, but CT pneumocolon had greater sensitivity and specificity for diagnosis larger polyps (over one $\mathrm{cm}$ ) [8]. Three invasive large intestine cancers which are detected, their size ranged between $3 \mathrm{~cm}$ and seven $\mathrm{cm}$, and 31 polyps for variable sizes). The results for all masses detected in the study are as follow: sensitivity is $(62 \%)$, specificity is $70 \%$ and also accuracy is $63 \%$ [8].

Furthermore, we found that mass detection by CT pneumocolon increased with increasing masses diameter. We have a tendency to hypothesize that the diagnosis of polyps would be possible with collimation of $8 \mathrm{~mm}$, also pitch of 1.5 , and reconstruction interval of $4 \mathrm{~mm}$. At the time of the study, the colon should be adequately cleaned and distended with air insufflation. These parameters allow supine scanning to be done during a single breath withhold in most all patients, with a radiation dose that it is the same as that of conventional barium enema $(5-7 \mathrm{mSv})$ [9]. In the present study, the sensitivity $(62 \%)$ was near to other reported sensitivity $60 \%-80 \%$ in some studies, that using thinner collimation, reconstruction interval and three dimensional reconstruction with specialized laptop computer software [10-12].

We also found that the site is an important factor for the detection of colon tumors, which is against previous studies which revealed that the site is of no value in detecting tumors [13].In our study, CT pneumocolon detected 3 polyps in the ascending colon and 6 polyps in the rectum and sigmoid colon. On the other hand, a large number of masses were found on the left side of the colon, mainly in the recto- sigmoid part. This is a common feature that corresponds to the distribution of pathological masses along with the four parts of the colon [14].

Finally, however not for small size bellow one $\mathrm{cm}$. In addition, CT pneumocolon provided clinically relevant information on cancer staging and extra-colonic abnormalities that weren't obtainable from endoscopy [15].

\section{Conclusions}

CT pneumocolon has high sensitivity and specificity for the detection of large-sized masses, but not for small ones.

\section{Recommendations}

CT pneumocolon may be suitable for investigating patients with symptomatic colorectal masses noninvasively.

Source of funding: This research was funded by ourselves and these is no other funding cover this study or manuscript preparation and publication. 
Ethical clearance: This study was approved by medical ethics committee of college of medicine ,university of Diyala.

\section{Conflict of interest: Nill}

\section{References}

[1]Gelfand DW. Gastrointestinal radiology: a short history and predictions for the future. AJR 1988; 150(6):717.

[2]Burling D; International Collaboration for CT colonography Standards. CT colonography standards. Clin Radiol 2010;65(6):474-480.

[3]Halligan S, Fenlon HM. Virtual colonoscopy. BMJ 1999; 319(7219):12491252.

[4]Vining DJ, Gelfand DW, Bechtold RE, Scharling ES, Grishaw EK, Shifrin RY. Technical feasibility of colon imaging with helical CT and virtual reality. AJR 1994; 162:104-106.

[5]Abu-Hamda EM, Erickson RA. Bumps in the Colon: Utility of EUS for Colonic Sub mucosal Masses, 2001; 57:315.

[6]Pochaczevsky R. Digital subtraction bowel cleansing in CT colonography. AJR Am J Roentgenol 2002;178(1):241.

[7]Steve halligan , Philip J.A Robinson . text book of radiology and imaging, seventh edition, London : churchill living stone : 2003 .chapter 21 , large bowel . Page 637.

[8]Miao YM, Amin Z, Healy J, Burn P, Murugan N, Westaby D, Allen-Mersh TG. A prospective single centre study comparing computed tomography pneumocolon against colonoscopy in the detection of colorectal neoplasms. Gut 2000; 47(6): 832-837.

[9]Iannaccone R, Laghi A, Catalano C, Mangiapane F, Lamazza A, Schillaci A, Sinibaldi G, Murakami T, Sammartino P,
Hori M, Piacentini F, Nofroni I, Stipa V, Passariello R. Computed tomographic colonography without cathartic preparation for the detection of colorectal polyps. Gastroenterology 2004;127(5):1300-1311. [10]Hara AK, Johnson CD, Reed JE, Ahlquist DA, Nelson H, MacCarty RL, Harmsen WS, Ilstrup DM. Detection of colorectal polyps with CT colography: initial assessment of sensitivity and specificity. Radiology 1997;205(1):59-65.

[11]Fenlon HM, Nunes DP, Schroy PC 3rd, Barish MA, Clarke PD, Ferrucci JT. A comparison of virtual and conventional colonoscopy for the detection of colorectal polyps. N Engl J Med 1999;341(20):1496503.

[12]Rex DK, Vining D, Kopecky KK. An initial experience with screening for colon polyps using spiral CT with or without CT colography (virtual colonoscopy). 2005; 514:54-45.

[13]Dobos N, Rubesin SE. Radiologic imaging modalities in the diagnosis and management of colorectal cancer. Hematol Oncol Clin North Am 2002;16(4):875-895. [14]Yee J, Kumar NN, Hung RK, Akerkar GA, Kumar PR, Wall SD. Comparison of supine and prone scanning separately and in combination at CT colonography. Radiology 2003;226(3):653-661.

[15]Lefere P, Gryspeerdt S, Baekelandt M, Van Holsbeeck B. Laxative-free CT colonography. AJR Am J Roentgenol 2004; 183(4): 945-948. 